\title{
The dynamics of sustainable innovation journeys
}

\section{Frank W. Geels , Marko P. Hekkert \& Staffan Jacobsson}

To cite this article: Frank W. Geels , Marko P. Hekkert \& Staffan Jacobsson (2008) The dynamics of sustainable innovation journeys, , 20:5, 521-536, DOI: 10.1080/09537320802292982

To link to this article: https://doi.org/10.1080/09537320802292982

Published online: 27 Oct 2008.

Submit your article to this journal ๘

山 Article views: 3057

Q View related articles $\sqsubset$

Citing articles: 138 View citing articles 


\section{EDITORIAL}

\section{The dynamics of sustainable innovation journeys}

\section{The contribution of innovation studies to the solution of persistent environmental problems}

Since the 1970s, environmental problems have risen on the political agenda. Many environmental problems (such as water pollution, local air pollution, acid rain) have since been solved or substantially reduced by policies and incremental clean technologies (e.g. fuel gas desulphurisation in power plants, three-way catalytic converters in cars), but other problems have grown worse, e.g. climate change, loss of biodiversity, deforestation, depletion of fish stocks and of clean water supplies. The incremental approach is less likely to work with these problems. With regard to climate change, for instance, global $\mathrm{CO}_{2}$ emissions must be cut by $80 \%$ by 2050 if the risks are to remain within acceptable limits (Stern 2006). It is difficult to achieve such cuts with incremental technical changes. Hence, more radical 'green' innovations are needed.

Although 'green' technologies with less $\mathrm{CO}_{2}$ emissions have emerged, their further development and the transformation of (fossil-fuel based) energy system into more sustainable directions will require a massive effort. This effort is massive for three reasons. First, the global energy system is extremely large and growing rapidly. The global power production increased from 6000 TWh in 1973 to 17,000 TWh in 2004, and is expected to grow to 25,000-35,000 TWh in 2050. Even with fossil-fuel or nuclear technologies it will be difficult to meet this growing demand. To transform this expanding energy system into carbon neutral directions will require even more effort, including large investments in the creation of new industrial structures. Second, the time scale for these changes is relatively short. Historical studies show that large scale transformation processes often takes many decades to unfold (Carlsson and Jacobsson 1997; Geels 2002). The challenge is to stabilise atmospheric $\mathrm{CO}_{2}$ concentrations in the next four decades (by 2050). This is difficult to achieve, because of timelags in the climate system. Analysts therefore estimate that we have a change window of about a decade to start reducing $\mathrm{CO}_{2}$ emissions (Stern 2006). Giving the previously mentioned expansion of energy demand, this time period forms an unprecedented challenge. Third, 'green' innovations face several obstacles that hinder rapid diffusion. Schumpeter $(1934,86-87)$ already noted that most innovations with a substantial degree of novelty face such problems: 
In the breast of one who wishes to do something new, the forces of habit rise up and bear witness against the embryonic project .... The reaction of the social environment against one who wishes to do something new, may manifest itself first of all in the existence of legal or political impediments..... Any deviating conduct by a member of a social group is condemned .... Even a mere astonishment at the deviation ... exercises a pressure on the individual.

Such obstacles are particularly large in the case of the energy system. Unruh (2000) therefore appropriately characterised the current situation as a 'carbon lock-in'. We mention three prominent problems.

(1) Initially, sustainable technologies tend to be more expensive and have lower performance (in mainstream dimensions) than existing technologies. Usually, market niches provide early footholds for radical innovations, with particular users accepting teething problems because the innovations offer advantages in that application domain. This mechanism is more complicated for 'green' innovations, because a clean environment is a collective good. 'Green' innovations provide benefits (reduced emissions) for society at large while costs are borne by individual users. The resulting (free rider) problems to form early niche markets hinder the innovation process (Jacobsson and Bergek 2004).

(2) Uncertainties about future market and regulations also hinder the commitment of firms to the development of sustainable technologies. On the one hand, many large energy firms and car manufacturers $d o$ invest in 'green' technologies, because they recognise the climate change problem (e.g. Shell in hydrogen, Toyota in hybrid cars, Ford in fuel cell cars). On the other hand, they do not (yet) fully commit to these innovations, because of market uncertainties and fear of cannibalising their existing products. Many green innovations therefore remain on the shelf or are paraded only on demonstration shows. The continuation of uncertainties prevents firms from strong commitment to the development and marketing of 'green' innovations.

(3) Existing technologies and sociotechnical systems are stabilised by lock-in mechanisms (Walker 2000; Unruh 2000). Long periods of dynamic increasing return (e.g. learning by doing and using, scale economies, network externalities) put them in advantageous positions. Standards, favourable regulations, sunk investments (in capital, competencies, social networks, infrastructures) and vested interests also provide existing technologies with stability. Subsidies (e.g. for coal), user lifestyles and behavioural patterns may provide further stability. Sustainable technologies may, therefore, face additional barriers when they have a 'mis-match' with aspects of existing systems (Freeman and Perez 1988). In sum, 'green' innovations do not compete with existing technologies on 'level playing fields'.

Continuing on the above discussion, we conclude that three often mentioned response strategies to environmental problems are insufficient. We briefly discuss these strategies and then introduce the fourth approach, which is central to this special issue.

(1) Neo-liberal strategies focus on 'getting the prices right'. Neo-liberal thinkers argue that environmental problems lead to scarcity, which translates into higher prices, which will trigger changes in the behaviour of consumers (demand for 'sustainable' products) and firms (investments to develop these products). Market failures may occur for collective goods, which require governments to introduce measures that internalise external costs (e.g. taxes, tradeable 
emission permits). For some environmental problems and under certain conditions (rational agents, full information, perfect markets) this approach can be effective and efficient, but it is more problematic for radical innovations and transitions, which are characterised by uncertainty about technologies, user preferences, and market institutions. In such conditions, rational calculations are likely to be less prominent than search processes, power struggles, learning and negotiations. Neo-liberal approaches are also less effective when there are no level playing fields on which old and new technologies can compete or when existing systems are stabilised by lock-in mechanism. Also the development of radical innovations, which may take decades as this special issue shows, is under-addressed in neo-liberal approaches (which sometimes portray new technologies as 'manna from heaven', i.e. exogenous events). Price signals alone are unlikely to deliver the speed of change required for dealing with climate change (only dramatic price increases may achieve this; but it is politically unfeasible to achieve this through heavy taxation, as the UK fuel protests a few years ago indicate).

(2) Ecological modernisation focuses on clean technology. This approach maintains a belief in core modernist principles such as science, technical progress, control, and economic growth. Instead of rejecting modernity, it wants reorientation into more sustainable directions (e.g. Mol 2001). Smart innovations and clean technologies are supposed to create win-win situations: continued economic growth and sustainable development. It rejects end-of-pipe solutions which only deal with effects, and shifts attention to sources such as industrial production processes, which need to be redesigned. Examples are process-integrated solutions, reuse and recycling, eco-efficiency, dematerialisation, closing of material loops (as in industrial ecology). Ecological modernisation introduces a welcome 'supply-side' perspective. Many critics, however, question its sufficiency for sustainable development and argue for more radical changes (e.g. Langhelle 2000; York, Van Driel, and Rosa 2003).

(3) 'Deep ecology' and eco-centrist approaches focus on 'green values' and behavioural change. These approaches argue that environmental problems are fundamentally related to the values of modernity. These values should therefore be rejected and replaced with 'deep green' life styles and localism (Næss 1973; Katz, Rothenberg, and Light 2000). Less radical versions exist, which may propose community-based initiatives where villages or neighbourhoods collectively adopt, maintain and administer 'green' technologies (e.g. biogas plants, solar panels, wind turbines), encouraging each other to change behaviour, roles and responsibilities (see Walker and Devine-Wright 2008, for an overview). While this approach usefully highlights social innovations, its radical overtones and (sometimes) technophobia may restrict it to a niche activity.

While these three approaches offer useful elements with regard to problems such as climate change, they are partial and insufficient to bring about the required system changes. They are also fairly abstract, addressing sustainability as a general issue. This special issue elaborates on a fourth position, socio-technical transitions, which addresses changes at a more concrete sectoral or systems level (Rochracher 2001; Jacobsson and Bergek 2004; Smith, Stirling, and Berkhout 2005; Geels 2005; Hekkert et al. 2007). This fourth position sees sustainability problems as a formidable societal challenge, whose magnitude is comparable to hygiene and infectious disease problems in nineteenth century 'Western' countries. The latter were addressed through a hygienic transition, which involved technical changes in water supply, sewer systems, housing and food, as well as behavioural changes in washing, bathing, relieving oneself, and cooking, and institutional innovations in local government and service provision (Geels 2006). In analogy, dealing with 
environmental problems requires shifts to new transport systems, energy systems, food systems, etc. Such transitions not only entail new technologies, but also changes in markets, user practices, policy and cultural discourses, and governing institutions. This fourth position thus aims to overcome the narrow focus of the previous approaches on either markets, technology or behavioural change. Hence, it looks at dynamic interactions and co-evolution between these elements, which as shorthand are labelled 'socio-technical'.

The socio-technical approach focuses on multiple actors and social groups, not only firms or consumers/markets. The appropriate analytical level is thus communities or organisational fields, which DiMaggio and Powell $(1983,148)$ define as:

those organizations that, in the aggregate, constitute a recognized area of institutional life: key suppliers, resource and product consumers, regulatory agencies, and other organizations that produce similar services or products. The virtue of this unit of analysis is that it directs our attention not simply to competing firms ..., or to networks of organizations that actually interact, ..., but to the totality of relevant actors.

Studied from an organisational field or community perspective (Van de Ven 1993), radical innovation implies not just the emergence of new knowledge and products, but also the creation of a new community, new networks and the rules/institutions that coordinate activities. Several terms have been advanced to emphasise heterogeneity, multi-dimensionality and co-evolution, e.g. 'seamless webs' (Hughes 1986), 'techno-economic networks' (Callon 1991), 'technological systems' (Carlsson and Stankiewicz 1991), 'socio-technical ensembles' (Bijker 1995), and 'techno-institutional complex' (Unruh 2000).

The multi-dimensionality of socio-technical change implies that sustainability transitions are complex processes. This special issue investigates these processes under the heading of 'sustainable innovation journeys'. We use the term 'innovation journey' to capture the open and uncertain nature of radical technological change, which is full of search and exploration processes, twists and turns, etc. ${ }^{1}$ The 'journey' aspect also highlights the agency dimension, with actors navigating, negotiating, and struggling their way forward (and sometimes backward as some articles will show). The term also indicates that a transition process can be characterised as a journey of which the final destination is not exactly known. There may be a sense of general direction (towards a sustainable society) but the precise journey changes as the traveller gains more knowledge and experience. We use the term 'sustainable' for two reasons. First, this special issue focuses on the dynamics of sustainable technologies, mainly in the energy domain, such as wind, solar and biopower, alternative fuels and low energy housing. Second, innovation journeys need to be sustained for long periods of time, often decades rather than years.

With regard to the four policy approaches discussed above, we observe that current sustainability debates are dominated by first and second position. This is unfortunate, in our view, because they are not appropriate for dealing with major environmental problems such as climate change and unlikely to bring about (with sufficient speed) the required structural changes and sustainability transitions. On these topics, innovation studies have important contributions to make to the debate, because of their insights in the dynamics of socio-technical change. These insights also have implications for the kinds of policy instruments that are considered in response to climate change. Economic instruments such as taxes, carbon trading, and R\&D subsidies currently dominate. While these instruments are important for socio-technical transitions, innovation studies' insights suggest additional policies that are related to networks, community building, visions, experiments/learning, etc. Socio-technical approaches refrain from simple policy recipes, 
because they highlight co-evolution, multi-dimensionality, complexity and multi-actor processes. They argue that constellations of policy instruments should vary, depending on specific challenges, opportunities and problems in sectors, technologies and social networks. While this message may be unpleasant for policy makers who hope for silver bullet solutions, we argue that a deeper understanding of socio-technical dynamics provides policy makers (and other actors) with a more solid base for policy interventions. This special issue aims to contribute to this deeper understanding and to provide insights into effective policy strategies.

Based on these considerations, the papers in this special issue are guided by the following questions:

(1) What are the micro-dynamics of innovation journeys? What are key processes and how should they be conceptualised?

(2) Which policy lessons can be drawn for managing sustainable innovation journeys?

With regard to the first question, we know that multiple disciplinary approaches and conceptual frameworks exist, some of which are used or elaborated in the different papers. Without aspiring to fully answer the first question, Section 2 briefly reflects on the reasons for this variety. That discussion also suggests that each disciplinary approach highlights some key processes and backgrounds others. More sophisticated frameworks therefore tend to arise from crossovers between approaches, something that all papers in the special issue practice. Building on this discussion, Section 3 not only introduces the papers, but also provides some tentative ideas on strengths and weaknesses of different frameworks.

The second question is briefly addressed in Section 4. Although we have just emphasised that policies should be tailored to particular contexts, this section articulates some robust policy findings that emerge from the papers in this special issue.

\section{Disciplinary approaches and crossovers}

Because socio-technical dynamics are multi-dimensional, insights from multiple disciplines are needed to understand the key processes. The following disciplines certainly are relevant in this respect: (1) (industrial and evolutionary) economics and management studies, (2) sociology (especially science and technology studies), (3) political science and (4) cultural studies. These disciplines highlight different analytical elements, ask different questions and open up different 'black boxes', which also means that they may be blind to other aspects.

(1) Economics (especially evolutionary economics and industrial economics) and management studies focus on elements such as: firms, entrepreneurs, competition between old and new technologies, competition between incumbent firms and new entrants, resources (e.g. competencies, money), adaptation and learning through $\mathrm{R} \& \mathrm{D}$, price/performance developments, industry structures and industrial networks, e.g. user-supplier networks. Broadly speaking then, the basic references are the market and the economy whereas society at large is taken for given. Much attention is given to the development of innovation and the formation of new industries. The black box of industrial dynamics is opened up but social embedding is seen as less problematic, or even ignored, and is conceptualised primarily as market adoption (diffusion). What users do with (new) technologies, how they integrate them in user practices, and how they may change their behaviour or preferences, receives less attention. 
(2) Sociology (especially science and technology studies) focuses on elements such as: relevant social groups, interpretations and views, motivations, meaning, cognitive frames and (second order) learning, social networks, negotiation and alignment. Broadly speaking, society is the basic reference point, in which the economy is embedded. STS-scholars 'opened up the black box' of technological change by 'following the actors' in their daily practices (e.g. inventors in the laboratory, engineers in design departments). Analysing the co-construction of technology and society, they also look at user contexts and dynamics in application domains (e.g. different user groups, their interpretations, interests, struggles, cultural meanings). But they often pay less attention to impersonal mechanisms such as market mechanisms, price/performance competition, resources.

(3) Political science focuses on elements such as: conflicting interests, power struggles, laws, regulations, institutional frameworks, lobbying, advocacy coalitions. Regulations and institutional alignment influence the societal embedding of new technologies while taxes and R\&D subsidies influence technological development. Policies are not seen as exogenous aspects that policy makers can influence at will. Instead, political science scholars open up the 'black box of politics', and show the power struggles and conflicts in the shaping of regulatory frameworks. Policy makers are influenced by their constituencies, support in Parliament, re-elections, public opinion, lobby groups, etc.

(4) Cultural studies focuses on elements such as: beliefs, discourses, societal legitimacy, values, social attitudes, social acceptance, cultural enthusiasm. Much attention is given to cultural embedding and social acceptance of new technologies. Culture, however, also influences the supply/development side. For instance, if a new technology has a negative symbolic meaning, this hinders the availability of private and public funding. Culture is not an epiphenomenon, but has real effects. Hence, actors engage in cultural struggles, using metaphors and symbols to influence discourses and shape legitimation processes. Cultural studies, thus, open up the 'black box of culture' underlining that culture is endogenous to sustainable innovation journeys, influencing both the development and societal embedding of new technologies.

The economic and sociological approaches are best represented within innovation studies, as indicated by dedicated professional societies, conferences and professional journals. Evolutionary economics, for instance, has the International Schumpeter Society, the Schumpeter conference, and the Journal of Evolutionary Economics as well as the more multidisciplinary Research Policy. Likewise, science and technology studies (STS) has the Society for the Social Studies of Science (4S) and The European Association for the Study of Science and Technology (EASST), the 4S and EASST conferences, and journals such Social Studies of Science and Science, Technology and Human Values. Political science and cultural studies appear to be less institutionalised on these dimensions, at least with regard to the topic of technological change.

The four disciplinary social science approaches each contain a variety of specific theories and perspectives regarding socio-technical change, which conceptualise interactions between relevant analytical elements in different ways. Restricting ourselves to the economic and sociological disciplines, it is not difficult to mention several approaches. Within evolutionary economics some approaches are: self-organisation and complexity theory, path dependence theories, and long wave theories. Some approaches in industrial economics are: industry life cycle approach, the innovation systems tradition, disruptive innovations and technological discontinuities. Within STS some approaches are: actor-network theory, social construction of technology, large technical systems theory. 
Table 1. Parent disciplines (+++) and crossovers to other disciplines $(+)$ of the papers in this special issue.

(Industrial and

evolutionary)

economics Sociology (STS) Political science Cultural studies

\begin{tabular}{lcccc}
\hline Schot and Geels & + & +++ & & \\
Verbong, Geels, and Raven & + & +++ & & \\
Bergek, Jacobsson, and Sanden & +++ & + & + & \\
Hillman, Suurs, Hekkert, and & +++ & + & + & +++ \\
$\quad$ Sanden & & & + & + \\
Lovell & & + & ++ & + \\
Agterbosch and Breukers & & & + & + \\
\hline
\end{tabular}

While these approaches and theories have recognisable 'parent' disciplines, some of them also make crossovers and try to incorporate elements from other disciplines. We want to strengthen a further move to such inter-disciplinary crossovers, because we are more interested in understanding a particular phenomenon (sustainable innovation journeys) than in elaborating disciplinary theories per se. Hence, the contributions to this special issue have been selected because they make such crossovers. While the papers in the special issue are 'rooted' in one of the four 'parent' disciplines, they all make crossovers to other disciplines (Table 1). The papers are multi-disciplinary in order to capture the complexity of socio-technical change.

\section{Introduction to the papers}

The six papers in this special issue focus on different countries (The Netherlands, Sweden, Germany and the United Kingdom) and use different perspectives on innovation journeys. Given the heterogeneity in the disciplinary backgrounds of the contributors, this variety in perspectives is not surprising, but it may be confusing to policy makers and other decision makers seeking ways to influence sustainable innovation journeys. In this section, we will, therefore make a lengthy introduction to the papers, showing how different frameworks conceptualise key processes in innovation journeys.

The first two papers elaborate on and apply the Strategic Niche Management (SNM) approach. The subsequent two papers use the related, yet different approach of Technological Innovation Systems (TIS), with an extension in terms of functional analysis. The final two papers reflect two other approaches: discourse analysis and historical new Institutionalism. These approaches share the view that innovation journeys are complex processes in which several elements and actors become aligned (or not). They also emphasise the ups and downs, and twists and turns of innovation journeys.

SNM initially emphasised the importance of local experimental projects to create 'protomarkets' where users, producers and other stakeholders can interact, learn and exchange experiences. SNM scholars emphasised that new technologies initially need some protection, because they cannot readily compete on mainstream markets (Kemp et al. 1998). Such protection can come from market niches with special selection criteria or from technological niches, such as pilot and demonstration projects. Later literature broadened the scope from single projects to an emerging community (Geels and Raven 2006).

Much SNM-work focuses on an intermediate development phase between R\&D and market introduction, where radical innovations need to cross the so-called 'valley of death'. In this 
relatively early phase, three key processes are distinguished: social network formation, learning processes, and articulation of expectations. ${ }^{2}$ Additionally, several sub-processes are identified, especially several dimensions of learning processes. Learning processes are crucial, not just to develop better knowledge and more facts, but also to develop shared meaning. Much attention is, therefore, given to socio-cognitive dynamics, such as conflicting interpretations and a gradual stabilisation of cognitive rules.

The first paper by Schot and Geels outlines the essentials of this influential school of thought. SNM's 'parent discipline' is sociology (STS) but it makes extensive crossovers to evolutionary economics. The paper reviews and discusses the intellectual development of the SNM approach over the past decade, in response to empirical findings and critical comments.

The second paper, by Verbong, Geels and Raven, applies the SNM approach to four renewable energy technologies in the Netherlands: photovoltaics, wind turbines, biomass (digestion, waste incineration, co-firing), and hydrogen (fuel cells). The paper analyses 30 -year innovation journeys for these technologies, showing recurrent patterns and policy failures. They conclude that learning processes were too much technology-push, focusing narrowly on $\mathrm{R} \& \mathrm{D}$, that social networks were closed and supply side oriented and that expectations followed hype-disappointment cycles, partly because policy makers had limited competence to assess promises by product champions.

The third paper, by Bergek, Jacobsson and Sandén, outlines the relatively new extension of technological innovation system (TIS) framework with a 'functions approach'. TIS was initially developed to capture whole transformation processes, including large scale diffusion of new technologies. The initial framework was applied, for instance, to mature technologies and whole sectors, such as factory automation and electronics (Carlsson 1997). Recent contributions in this tradition focus more on early phases in the development of a TIS, distinguishing between key processes at structural and functional levels. Processes at the structural level include entry of organisations, formation of networks and institutional alignment. In this respect TIS builds on industrial economics (and management science) where entry (and exit) patterns have always been central drivers of industrial dynamics, e.g. by influencing division of labour and the formation of legitimacy for new industrial fields. ${ }^{3}$

While its 'parent discipline' is industrial economics (and economics of innovation), the TIS approach attempts to make substantial crossovers to political science and sociology, whereas factors within cultural studies are included in an ad-hoc manner only. Crossovers are visible both in attempts to incorporate insights such as political aspects of institutional alignment and in the diverse set of key processes at the functional level, which denotes essential dimensions of what is 'achieved' in the system. Eight dimensions are specified (development of formal knowledge, entrepreneurial experimentation, materialisation, influence on the direction of search, market formation, resource mobilisation, legitimation and development of positive externalities). ${ }^{4}$ The paper by Bergek et al. focuses on two of these key processes: 'legitimation' and 'development of positive external economies' (primarily in the Swedish power and transport sectors) and draws implications for both policy makers and managers.

The fourth paper, by Hillman, Suurs, Hekkert and Sandén, applies a variation of the approach 'functions of innovation systems' to the development of alternative fuels in the Netherlands and Sweden. Particular attention is given to the conditions under which cumulative causation takes place. The contrasting outcomes between the Netherlands and Sweden (where technical developments and early market formation have progressed further) add weight to the critique of Dutch policy in Verbong et al.

Both SNM and TIS papers focus broadly on multiple dimensions of innovation journeys. The other two papers (Lovell, Agterbosch and Breukers) focus deeper on specific dimensions. 
Lovell's parent discipline is cultural studies, but she makes crossovers to political science. She examines the role of discourse in innovation journeys using the example of low energy housing in the UK (1970-2007). Discourse is shown to unite disparate organisations (which form discourse coalitions), giving structure and direction to innovation journeys. She uses the concept of discursive framing to explain how such coalitions of actors frame sustainable housing innovations as a solution to different policy problems. Such framings are particularly important in the development stage when an innovation needs to gain recognition and visibility among a wider pool of actors. While the paper focuses on one key process (discursive framing), it also highlights associated political and power dimensions.

The empirical analysis shows that an initial framing was made in the context of a social movement of 'radical deep green environmentalism'. A reframing occurred in the 1990s by a low carbon discourse coalition (adopting an ecological modernisation repertoire). This reframing not only accelerated the innovation journey but also reshaped the interpretation of sustainable housing solutions away from the original 'deep ecology' concept, emphasising energy and technology more than waste, water, life styles and other 'softer' issues. The analysis also shows that materialisation through demonstration projects influenced and strengthened the discourse, supporting in a way SNM's emphasis on concrete experimentation and pilot projects.

TIS and SNM can learn from Lovell's in-depth analysis of discourse, which not only influences the framing of problems and opportunities, but also reflects power relations. These insights could provide more depth to the function 'influence the direction of search' in TIS and the key process of 'shaping of expectations' in SNM.

Agterbosch and Breukers' parent discipline is political science but they make crossovers to sociology and cultural studies. They address socio-political processes in innovation journeys, focusing on struggles over interests (e.g. local vs national or global) and cultural meaning (wind turbines as either 'landscape pollution' or symbols of environmental/economic progress). The key process is 'socio-political embedding' which involves the alignment of (formal and informal) institutions and new technology.

The article makes a comparative analysis of the Netherlands and the German state of Nord Rhine Westphalia. The authors apply historical new-institutionalism to assess how the specific institutions in the two 'countries' influenced the socio-political processes of policy generation and implementation at the local level. The analysis emphasises 'institutional alignment', demonstrating in particular how a confluence of policies in energy, spatial planning and environmental domains shaped the implementation process. The paper also highlights the importance of involving locally based investors and grass root movements (as opposed to energy companies) to gain sociopolitical legitimacy and it demonstrates the inherently political nature of innovation journeys, with actors struggling over interests and cultural meaning. Diffusion and social embedding of new technologies is thus not only a market-driven process, but also entails power struggles and social acceptance, which is influenced by socio-political legitimacy (also the TIS approach distinguishes 'legitimation' as a key process). These insights are also important for the broader political economy of climate change policies, where understanding power relations, and how these may be altered, is critical. Environmental policy making and implementation is not simply managerial. Because power relations are crucial, further analysis of the 'politics of policy' (Jacobsson and Lauber 2006) is called for.

The key processes identified above are internal to an emerging entity (socio-technical ensemble, seamless web, innovation system). The key processes are linked and may strengthen, or weaken, each other. So, positive feedbacks or 'cumulative causation' (Myrdal 1957) are crucial for innovation journeys. 
This does not mean that innovation journeys are only driven by endogenous dynamics. External influences from broader contexts are also important. Especially in early phases of development, when innovative novelties are weak and fragile, favourable external contexts (or expectations of it) play important roles. Internal-external interactions are therefore crucial for innovation journeys. More than 50 years ago, Myrdal $(1957,18)$ formulated the following guiding principle:

... the main scientific task is ... to analyse the causal inter-relations within the system itself as it moves under the influence of outside pushes and pulls and the momentum of its own internal processes.

With regard to innovation journeys and transitions, this principle is explicitly elaborated in the multi-level perspective (MLP), in which SNM is contextualised. Distinguishing between regimes and socio-technical landscapes as two kinds of external context, Schot and Geels (2008) explicitly argue that:

The core notion of the multi-level perspective (MLP) is that transitions come about through interactions between processes at different levels: (a) niche-innovations build up internal momentum, through learning processes, price/performance improvements, and support from powerful groups, (b) changes at the landscape level creates pressure on the regime, (c) destabilisation of the regime creates windows of opportunity for niche-innovations.

In the TIS approach, the distinction between internal and external is, perhaps, less visible, but nonetheless very much there. Indeed, the whole notion of functions was developed to handle an integration of technology-specific and more contextual factors that promote or hinder the development of various functions (Johnson and Jacobsson 2001, 93):

In the context of an emerging technological system, these factors may be fully technology specific, but may influence several technological systems simultaneously. Hence, they can be derived from a system perspective using different units of analysis: technology, industry, nation.

Hence, driving forces and obstacles to system development are seen as both internal and external (see Section 1 for a discussion of some external obstacles). While TIS and SNM/MLP thus both made a distinction in terms of 'levels', it seems fair to say that the MLP has progressed further in conceptualising interactions between internal and external processes. The energy domain, which is the empirical focus of the special issue, is particularly complex in this respect, because of influences from multiple regimes. For wind power implementation, for instance, Agterbosch and Breukers showed the influence from energy, spatial planning and environmental policy domains. Schot and Geels (2008) therefore propose that multi-niche and multi-regime interactions are important items for future research.

In sum, the papers in this special issue identify a range of key processes. Although the four conceptual frameworks in the papers are multidisciplinary, they still reflect their parent disciplines and therefore highlight specific parts of the 'elephant' whilst playing down or neglecting other parts. To more fully comprehend the dynamics of socio-technical transitions, and support the development of appropriate responses to the climate threat, more crossovers may be needed. While this special issue already demonstrates the fruitfulness of such crossovers, we believe this avenue can be further explored. A clear challenge, from a policy perspective, is to consolidate this richness into a common set of core concepts that can be used to inform policy makers. We hope that future research will continue to synthesise the rich literature on innovation and socio-technical change, and develop multidisciplinary understandings that can inform policy makers, entrepreneurs and 
other stakeholders who have an interest in sustainable innovation journeys. In the context of climate change policy, there is a particular need to understand better how the process from the initial 'niche' to a large scale transformation can be accelerated. To understand this take-off dynamic, we need to learn more about positive feed-backs between endogenous processes and the influences of external contexts. This is not just a theoretical endeavour, but also a challenge for empirical work and case studies, particularly when regularities, patterns or robust findings can be derived. On that note, the last section of this article describes some robust policy lessons that emerge from the empirical studies in the special issue.

\section{Policy lessons}

Although the papers differ in their precise conceptual frameworks, we draw seven robust policy lessons from their empirical analyses of sustainable innovation journeys.

First, early market formation is an important process. This is a core idea in both SNM and TIS. Kemp, Schot, and Hoogma (1998) formulate it well:

Without the presence of a niche, system builders would get nowhere ... . Apart from demonstrating the viability of a new technology and providing financial means for further development, niches help building a constituency behind a new technology, and set in motion interactive learning processes and institutional adaptation ... that are all-important for the wider diffusion and development of the new technology. (Kemp, Schot, and Hoogma 1998, 184, our emphasis)

For radical innovations, new markets thus co-develop with new technologies. This view deviates from the linear model, to which many policy makers still adhere, which sees markets materialise after a technology is fully developed. Hillman et al. (2008) show that the Dutch inability to form markets for second generation biofuels hindered the innovation journey, because two technology alliances (the Shell-ECN and the TNO networks) subsequently decided not to build commercial plants. Their contrasting case study of Swedish ethanol and other alternative fuels demonstrates what can happen if early markets are formed: investments, materialisation of the technology, and build-up of a constituency further influenced the institutional framework.

Second, consistent and stable policy frameworks are important for innovation journeys, because entrepreneurs need (at least some) stability to make cost/benefit calculations of strategic investments. The papers by Verbong, Geels, and Raven and by Agterbosch and Breukers provide negative cases, where the persistent volatility of Dutch renewable energy policy is a key factor behind failures of many sustainable innovation journeys. A positive example is the relative stability of the German policy regime, centred on the feed-in law and an associated reduction of uncertainties for investors.

Third, social embedding of technology and socio-political legitimacy are important, for both early market formation and further up-scaling. Policy makers often fail to handle this challenge, or only recognise its importance when it is too late (perhaps a consequence of adhering to a linear model). Agterbosch and Breukers, for instance, found such policy failures for wind power (but it may well become a central issue for biofuels as well). Therefore, they conclude that policy makers should address legitimation as a central issue and not as an afterthought to the development and diffusion of new technologies:

Ex ante evaluation of renewable energy policy with regard to tensions in motives, interests, perceptions and possibilities for different stakeholders at different levels of government is important to foster sociopolitical embedding. Such an evaluation starts with the acknowledgement of the political nature of 
innovation journeys and asks for an institutionalisation of participation of relevant stakeholders in policy and planning and decision-making. (our emphasis)

The political and cultural dimensions of social embedding and legitimation imply that technology push policies, with a primary focus on technological learning, have major limitations. Because innovation journeys are co-evolution or co-construction processes, other 'softer' issues need to be handled in parallel with the technological ones. Based on the analysis of four Dutch innovation journeys, Verbong, Geels, and Raven (2008) draw the following critical conclusion:

All niche-innovation trajectories were characterised by a technology push approach, focussing primarily on R\&D. Other dimensions of learning and articulation processes were relatively neglected (e.g. commercial prospects, societal embedding, legal procedures, societal stakeholders). This neglect negatively influenced subsequent implementations. Regarding MCFC, for instance, warnings about the lack of commercial feasibility were consistently ignored, contributing to failure in the first phase. Lack of attention for social acceptance of renewable energies led to major problems with wind turbines and biomass, which both experienced fierce opposition.

Tentative societal experiments with new technologies are one way of testing or articulating social acceptance, especially when many kinds of stakeholders are seriously involved. Lovell (2008) shows that such demonstration or pilot projects may influence broader discourses, which influence legitimacy. Through providing material evidence (of low carbon practices) such projects can provide credence to particular storylines. Lovell therefore emphasised the importance of the first materialisation of a new technology:

The story lines ... have ... helped speed up the innovation journey, because their material existence has acted to convince others - government, business and householders - of the economic and technical feasibility of low carbon housing ... in other words, the innovative dwellings literally lend substance to the discourse coalition's arguments, and have helped sustainable housing to be viewed as a credible solution to climate change.

Fourth, multiple innovation journeys may reinforce each other, especially when they collectively provide legitimacy for certain normative visions (e.g. sustainable development) and build up support for policy changes. Bergek, Jacobsson, and Sandén (2008) therefore argue that 'packs of entrepreneurs' from different innovation journeys may collectively engage in institutional entrepreneurship. The relatedness of such 'packs' may simply consist of supporting the notion of 'renewable energy'. Drawing on case studies of alternative transport fuels in Sweden and renewable power in Germany, they demonstrate that interactions between multiple innovation journeys can generate positive external economies that flow across TIS. Such interactions thus lead to a powerful 'bottom-up' process of institutional alignment and growth. Bergek, Jacobsson, and Sandén, argue that this has implications for management and policy.

For managers, it becomes essential to align the interests of advocates of several 'competing designs' and, in particular, to work across TIS by forming broader advocacy coalitions. Policy makers need to support such broader coalitions by selecting support schemes that do not pit various emerging TIS against each others in a misguided notion of efficiency. Instead, they should favour regulatory frameworks that stimulate the generation of a diverse set of technological options in parallel.

A fifth issue is the role of incumbents and new entrants in social networks. Large incumbent firms may not be interested in supporting sustainable innovation journeys, because these may 
threaten their existing products or because they perceive them as uninteresting. This may lead to a lack of investments and difficulties in forming early markets. The technology management literature therefore suggests that new entrants (often small start-up, entrepreneurial firms) are important for developing radical innovations, but we also know that new entrants often fail, because of low legitimacy, lack of political clout, limited resources or insufficient competencies. The incumbent-new entrant issue is one of several policy dilemmas that Schot and Geels (2008) identify. On the one hand, incumbents have many resources and may speed up innovation journeys if they commit themselves. Therefore, policy makers often rely on incumbents to foster new technologies. Agterbosch and Breukers (2008), for instance, show that Dutch policy makers relied on incumbents (e.g. large utilities) to drive wind power until the end of the 1990s. On the other hand, incumbents may have limited motivation or intention to push things forward, as happened in the Dutch wind turbine case. In contrast, the German feed-in law of 1991 explicitly excluded utilities, based on a different economic philosophy that valued new entrants (see Toke and Lauber 2007). Real policy dilemma's have no simple solutions; appropriate answers in one context may not work in another. Policy makers should have sufficient competence to make such assessments, an issue we now turn to.

Sixth, policy makers should have sufficient competence and substantive expertise of the technologies (problems, potential) and the social networks. That way they can better assess the quality of promises from product champions and the motivations of actors (such as the incumbents discussed above). Several papers in the special issue show that this is not always the case. Lovell describes how a low carbon discourse coalition hijacked the innovation journey of low energy housing in the UK, reframing its broad orientation (on waste, water, lifestyles) to a more narrow focus on technology and energy (climate change). The new discourse coalition sidelined the previous network, because it politically and financially more rewarding to frame the innovation journey as 'low carbon'. Policy makers need to be competent enough to not passively go along with such reframing. Bergek, Jacobsson, and Sandén make a similar plea, arguing for a competence base that permits decision makers to critically assess attempts to shape expectations and normative legitimacy, in particular by incumbents with larger resources and greater access to media. Verbong, Geels, and Raven also identify limited competence and poor policy learning as a key factor behind Dutch failures in sustainable innovation journeys. They identify hype-cycles in Dutch policy, caused by policy makers uncritically accepting promises of product champions, followed by disappointments when setbacks occur.

Seventh, because sustainable innovation journeys are multifaceted, policies need not be limited to R\&D subsidies and changing relative prices (as economists and model building engineers often think). Innovation journeys are shaped by not only economic, but also social, political and cultural factors. Policy makers should acknowledge this multifaceted nature of innovation journeys, and use a variety of policy instruments. From the relative success of Swedish alternative fuels, Hillman et al. draw the lesson that a broad policy orientation is needed, which addresses multiple functions and, thereby contributing to build a complete TIS:

... policy measures are most effective when designed to target all the TIS functions. Also entrepreneurs are most successful in bringing about change when actions are directed at facilitating multiple system functions; this is actually what makes cumulative causation possible .... The possible advantages of a broader policy orientation is shown by the variety of actions taken by the national Swedish government. Besides guidance, Swedish policy targeted knowledge formation, but also ... early entrepreneurial experiments and the (niche) market activities around $1 \mathrm{G}$ biofuels ... . (Our emphasis) 


\section{Editorial}

The challenge is, thus, to avoid the temptations of the 'linear model' and adopt a broader conceptualisation that addresses the multi-dimensionality of technological niches, technological innovations systems or other terms that analysts use to highlight the intrinsic interrelatedness of socio-technical change (e.g. seamless webs, socio-technical ensembles). We hope this special issue has contributed to developing this broader conceptualisation.

\section{Acknowledgements}

The papers in this special issue were presented and discussed at a workshop in Utrecht, in October 2006. We are very grateful not only to the participants, but also to the sponsors, VINNOVA and KSI (Knowledge network on System Innovation), for making this workshop a success.

\section{Notes}

1. The term 'innovation journey' has been defined by van de Ven et al. (1999, 6-7) as 'new ideas that are developed and implemented to achieve desired outcomes by people who engage in transactions (relationships) with others in changing institutional and organizational contexts' (italics in original). Where van de Ven et al. (1999) focused on innovation journeys within organisations, we will focus on sustainable innovation journeys at the level of societies, sectors and nations.

2. Because of its focus on relatively early phases, SNM is less explicit about further diffusion. More attention could be given to the subsequent 'take-off' phase. As the stock of a particular technology increases 100 or even 500 times, we may need to know more about the mobilisation of resources (money, competencies). This might require more understanding of the capital market and adjustments in the educational system to 'produce' the required skills. Also the entry of new organisations seems an important process for take-off, because of its influence on resource mobilisation, division of labour (specialised suppliers), scale economies, etc. In our view, SNM might benefit from insights in industrial economics, where a rich literature has addressed these kinds of issues (e.g. Smith, Marx, Marshall, Young, Rosenberg).

3. Because of different disciplinary backgrounds, 'functions in innovation systems' has a more economics/ entrepreneurial flavour and SNM a more socio-cognitive one.

4. Hillman et al. (2008) uses seven functions, where some differ from those used by Bergek, Jacobsson, and Sandén (2008).

\section{References}

Agterbosch, S., and Breukers, S. 2008. Socio-political embedding of onshore wind power in the Netherlands and North Rhine-Westphalia. Technology Analysis \& Strategic Management 20, no. 5: 633-48.

Bergek, A., S. Jacobsson, and B.A. Sandén. 2008. 'Legitimation' and 'development of external economies': two key processes in the formation phase of technological innovation systems. Technology Analysis \& Strategic Management 20, no. 5: 633-48.

Bijker, W.E. 1995. Of bicycles, bakelites and bulbs: towards a theory of sociotechnical change. Cambridge, MA: The MIT Press.

Callon, M. 1991. Techno-economic networks and irreversibility. In A sociology of monsters: essays on power, technology and domination, ed. J. Law, 132-61. London: Routledge.

Carlsson, B., and R. Stankiewicz. 1991. On the nature, function and composition of technological systems. Journal of Evolutionary Economics 2, no 1: 93-118.

Carlsson, B., and S. Jacobsson. 1997. Diversity creation and technological systems: a technology policy perspective. In Systems of innovation: technologies, institutions and organizations, ed. C. Edquist. London: Pinter.

Carlsson, B., ed. 1997. Technological systems and industrial dynamics. Boston, MA: Kluwer Academic.

DiMaggio, P.J., and W.W. Powell. 1983. The iron cage revisited: institutional isomorphism and collective rationality in organizational fields. American Sociological Review 48: 147-60.

Freeman, C., and C. Perez. 1988. Structural crisis of adjustment, business cycles and investment behaviour. In Technical change and economic theory, eds. G. Dosi, C. Freeman, R. Nelson, G. Silverberg and L. Soete, 38-66. London: Pinter. 
Geels, F.W. 2002. Technological transitions as evolutionary reconfiguration processes: a multi-level perspective and a case-study. Research Policy 31, no. 8-9: 1257-74.

- 2005. Technological transitions and system innovations: a co-evolutionary and socio-technical analysis. Cheltenham: Edward Elgar.

- 2006. The hygienic transition from cesspools to sewer systems (1840-1930): the dynamics of regime transformation. Research Policy 35, no. 7: 1069-82.

Geels, F.W., and R.P.J.M. Raven. 2006. Non-linearity and expectations in niche-development trajectories: up and downs in Dutch biogas development (1973-2003). Technology Analysis \& Strategic Management 18, no. 3-4: 375-92.

Hekkert, M.P., R.A.A. Suurs, S.O. Negro, S. Kuhlmann, and R.E.H.M. Smits. 2007. Functions of innovation systems: a new approach for analysing technological change. Technological Forecasting and Social Change 74, no. 4: 413-32.

Hillman, K.M., R.A.A. Suurs, M.P. Hekkert, and B.A. Sandén. 2008. Cumulative causation in biofuels development: a critical comparison of the Netherlands and Sweden. Technology Analysis \& Strategic Management 20, no. 5: 593-612.

Hughes, T.P. 1986. The seamless web: technology, science, etcetera, etcetera. Social Studies of Science 16, no. 2: 281-92.

Jacobsson, S., and V. Lauber. 2006. The politics and policy of energy system transformation - explaining the German diffusion of renewable energy technology. Energy Policy 34, no. 3: 256-76.

Jacobsson, S., and A. Bergek. 2004. Transforming the energy sector: the evolution of technological systems in renewable energy. Industrial and Corporate Change 13, no. 5: 815-49.

Johnson, A., and S. Jacobsson. 2001. Inducement and blocking mechanisms in the development of a new industry: the case of renewable energy technology in Sweden. In Technology and the market, demand, users and innovation, eds. R. Coombs, K. Green, A. Richards and W. Walsh. Cheltenham: Edward Elgar.

Katz, E., D. Rothenberg, and A. Light, eds. 2000. Beneath the surface: critical essays in the philosophy of deep ecology. Cambridge, MA: MIT Press.

Kemp, R., J. Schot, and R. Hoogma. 1998. Regime shifts to sustainability through processes of niche formation. The approach of strategic niche management. Technology Analysis and Strategic Management 10, no. 2: 175-95.

Langhelle, O. 2000. Why ecological modernization and sustainable development should not be conflated. Journal of Environmental Policy \& Planning 2: 303-22.

Lovell, H. 2008. Discourse and innovation journeys: the case of low energy housing in the UK. Technology Analysis \& Strategic Management 20, no. 5: 613-32.

Mol, A.P.J. 2001. Globalization and environmental reform: the ecological modernization of the global economy. Cambridge, MA: MIT Press.

Myrdal, G. 1957. Economic theory and underdeveloped regions. London: Ducksworth.

Næss, A. 1973. The shallow and the deep, long-range ecology movement. Inquiry 16: 95-100.

Rohracher, H. 2001. Managing the technological transition to sustainable construction of buildings: a socio-technical perspective. Technology Analysis \& Strategic Management 13, no. 1: 137-50.

Schot, J., and Geels, F.W. 2008. Strategic niche management and sustainable innovation journeys: theory, findings, research agenda, and policy. Technology Analysis \& Strategic Management 20, no. 5: 537-54.

Schumpeter, J.A. 1934. The theory of economic development: an inquiry into profits, capital, credit, interest, and the business cycle. Cambridge, MA: Harvard University Press.

Smith, A., A. Stirling, and F. Berkhout. 2005. The governance of sustainable socio-technical transitions. Research Policy 34: 1491-510.

Stern, N. 2006. Stern review on the economics of climate change. London: H.M. Treasury, United Kingdom.

Toke, D., and V. Lauber. 2007. Anglo-Saxon and German approaches to neoliberalism and environmental policy: the case of financing renewable energy. Geoforum 38: 677-87.

Unruh, G.C. 2000. Understanding carbon lock-in. Energy Policy 28: 817-30.

Van de Ven, A.H. 1993. A community perspective on the emergence of innovations. Journal of Engineering and Technology Management 10: 23-51.

Van de Ven, A.H., D.E. Polley, G. Garud, and S. Venkataraman. 1999. The innovation journey. Oxford: Oxford University Press.

Verbong, G., F.W. Geels, and R. Raven. 2008. Multi-niche analysis of dynamics and policies in Dutch renewable energy innovation journeys (1970-2006): hype-cycles, closed networks and technology-focused learning. Technology Analysis \& Strategic Management 20, no. 5: 555-73.

Walker, W. 2000. Entrapment in large technology systems: institutional commitments and power relations. Research Policy 29, no. 7-8: 833-46.

Walker, G.P., and P. Devine-Wright. 2008. Community renewable energy: what should it mean? Energy Policy 36: $497-500$. 


\section{Editorial}

York, R., H. Van Driel, and E.A. Rosa. 2003. Key challenges to ecological modernization theory. Organization \& Environment 16, no. 3: 273-88.

Frank W. Geels Department of Technology Management Eindhoven University The Netherlands

Marko P. Hekkert Copernicus Institute for Sustainable Development and Innovation Universiteit Utrecht The Netherlands

Staffan Jacobsson Environmental Systems Analysis, Department of Energy and Environment Chalmers University of Technology Gothenburg, Sweden 